nerve-tissue. There were no traces of pus and the cerebellum was uninjured.

In how far the pigeon deprived of labyrinths perseived sound it is almost impossible from the nature of the reactions to say; but the same may be said in regard to the normal bird.

The facts that the reactions increased with the intensity of the sounds and that reactions on a new sound followed inaction after a series of like sounds would seem to indicate a perception of quantitative and qualitative differences in the stimuli. But at any rate this evidence, together with the experiments on the intercranial conduction of tones, make it highly probable that the action of the labyrinth is not essential to the perception of sound.

F. ANgri.

STANPORD UNTERESTYY.

\title{
THE PERCEPTION OF DISTANCE.
}

Das Verhalmis von Accommodation und Konvergene zur Tiefenlokalisation. Frunz Hrllebrand. Zeitsch. f. Psychol, vil. 97-15x. 1894 .

This article reports the following experiments: An apparatus is 80 arranged that the subject, with one eye closed, looks with the other through a tube whose further end is closed by a diaphragm with an opening measuring $1 \mathrm{~cm} \times 1.5 \mathrm{~cm}$; and fixates the sharply-cut vertical edge of a piece of black cardboard which fills up one half of the field of view, the other half being occupied by a brilliantly-illuminated white glass plate, which forms a background at a distance of a little more than one meter from the eye. The black cardboard can be moved smoothly backward and forward, its edge retaining constantly the same position in the field of view. By this arrangement all 'empirical' factorsvarying size of retinal image, double-images on the two retina, etc.which might reveal the distance of the edge fixated are excluded, and it becomes possible to determine the infuence of accommodation and of the convergence which accompanies it even when one eye is closed. Experiments performed under these conditions showed :

1. That when the fixated object was moved backward or forward within the range of easy accommodation, and with a rapidity which allowed it to be constantly accommodated for, it was impossible to tell with any accuracy whether the object was moved nearer or farther away.

2. That when the fixated object changed its distance so suddenly that it was impossible to follow it with accommodation, cach observer was able to tell accurately in which direction the movement had taken place, if the difference in distance was sufficiently great. 
In another series of experiments, in place of the black cardboand was substituted another cardboard with an adjustable diaphragm which entirely concealed the white background except so much as could be seen through the diaphragm. If now the opening remained unchanged in distance but was made smaller or larger, the observer obtained the impression of an increase or decrease in distance, although accommodation and convergence did not alter. If the cardboard was moved nearer, and the opening at the same time was more than proportionally diminished, then in spite of increasing strain of accommodation the observer believed that the object had been moved farther away.

From these results Dr. Hillebrand concludes that accommodation and convergence, when thus isolated, give us no information in regard to the distance of the point of fixation; in other words, that 'so-called muscle-sensations' have no existence, or at least have no importance in visual localization. Without them it is easy to explain the results mentioned under (2) above, on the supposition that when the change in distance is sudden the observer voluntarily changes his accommodation, and knows, since it is voluntary, whether the new accommodation is for a nearer or farther object; and hence knows also whether the object has moved nearer or farther away, because if his first change of accommodation has not succeeded in making the image of the object clearer, a second change in the opposite direction will do so. When, however, the change in accommodation is involuntary, as in the experiments under ( $\mathrm{r}$ ), there is no means of knowing the direction or even the fact of movement, since, as these experiments establish, the changes in accommodation and the always accompanying changes in convergence yield no muscle-sensations to reveal the nature or the existence of these changes.

E. B. Delabarre.

Brown UNIVIrasty.

\section{ASSOCIATION, REACTION.}

Minor Studies from the Psychological Laboratory of Cornell University. Communicated by E. B. Titchener. I. 'Mediate' Association. H. C. Howe. II. 'Sensorial' and 'Muscular' Reattions. A. R. Hruz and R. Watanabe. Am. Jour. of Psychol, vi. 239-246. Jan. $x 894$.

-Professor Titchener contributes the first-fruits of the Psychological Laboratory of Cornell University, from which much admirable work in experimental psychology may be expected. Mediate association and sensory and muscular reactions seem to be receiving more than their due share of attention just now, but these experiments are presented in a concise form which should serve as a model. 